\title{
Mathematics Education at Tertiary Level and Access to Tertiary Level
}

\author{
Ansie Harding and Juha Oikkonen
}

\section{Structure of TSG2 Sessions}

TSG 2 had 4 sessions of 90 min each, themed as follows:

- Session 1: Teaching philosophies and professional development

- Session 2: Teaching practices

- Session 3: Student experiences/learning, also e-learning

- Session 4: Transition from school to university

The four sessions were all structured similarly. Presentations were classified as either long (15 $\mathrm{min})$ or short $(10 \mathrm{~min})$. A session started with one long presentation followed by four or five short presentations (20 presentations in total). Each session closed with a discussion of $15 \mathrm{~min}$. In addition three posters were discussed in the third session and displayed in the exhibition area.

Organizers Co-chairs: Ansie Harding (South Africa), Juha Oikkonen (Finland); Team Members Christopher Sangwin (UK), Sepideh Stewart (New Zealand), Miroslav Lovric (Canada), Sung-Ock Kim (Korea); Liaison IPC Member: Johann Engelbrecht (South Africa).

\author{
A. Harding $(\bowtie)$ \\ University of Pretoria, Pretoria, South Africa \\ e-mail: aharding@up.ac.za \\ J. Oikkonen \\ University of Helsinki, Turku, Finland \\ e-mail: Juha.Oikkonen@helsinki.fi \\ (C) The Author(s) 2015
}




\section{General Comments}

We are happy to report that TSG 2 ran smoothly and encountered no problems whatsoever. The team worked well together in organising the event before the time. Everyone stuck to deadlines and was forthcoming in suggestions and comments. During the conference itself the team members acted as chairs of the four sessions, respectively, and managed to create coherence amongst the attendees. The sessions were all well attended, drawing approximately 40 delegates per session. It was noticeable that many delegates seemed to develop a sense of belonging to TSG 2 and attended throughout. They were spontaneous in presenting questions and comments, especially during discussion sessions. Unfortunately co-chair Juha Oikkonen had to cancel attendance shortly before the conference on grounds of a medically related problem. He was extremely disappointed not to attend, having contributed in every respect to organizing TSG 2 .

\section{Comments Per Session}

\section{Session 1: Teaching Philosophies and Professional Development}

This session kicked off with a presentation by the well-known twosome John and Annie Seldon, from the USA, a well-received presentation addressing the issue of student success in problem solving. This presentation was followed by four speakers giving an Iranian (Khakbaz Azimeh Sadat), Irish (David Wraith \& Anne O'Shea) and Canadian (Miroslav Lovric) perspective, respectively, on related topics. The final presentation in this session was by Leigh Wood from Australia reporting on graduate skills necessary for successful transition from university to the professional environment.

- Annie Selden \& John Selden: A Belief Affecting University Student Success in Mathematical Problem Solving and Proving

- Khakbaz Azimeh Sadat: How do Iranian Graduate Students Learn to Teach Collegiate Mathematics as Future Mathematics Professors?

- David Wraith \& Anne O'Shea: The use of problem-solving techniques as a learning tool in university mathematics courses

- Miroslav Lovric: Learning Mathematics in an Interdisciplinary Science Program

- Leigh Wood: Preparing our graduates for the workforce 


\section{Session 2: Teaching Practices}

This session started with a team of young but extremely competent educators from Finland describing an effective system introduced into tutorial sessions. Their enthusiasm added to the success of the session. The subsequent presentations described teaching practices from a variety of countries and a variety of perspectives, providing ample material for discussion.

- Terhi Hautala, Tiina Romu, Thomas Vikberg, Johanna Ramo: The Extreme Apprenticeship Method in Teaching Mathematics at University Level

- Olof Viirman: The Teaching of Functions as a Discursive Practice? University Mathematics Teaching from a Commognitive Standpoint

- Tolga Kabaca: Teaching the Cycloids by the use of Dynamic Software: Abstraction Process of Hypocycloid and Epicycloids Curves

- Liu Jiao \& Yao Jing: The Application of Problem-based Learning in Higher Vocational Mathematics Teaching

- Rad Dimitric: Feedback from students' exams. A case study.

\section{Session 3: Student Experiences/Learning, also E-Learning}

The first presentation in this session was by Sepideh Stewart from New Zealand speaking on reactions of students to a particular approach to Linear Algebra. The presentation was informative and eloquently presented. Presentations focussed on how students learn and their experiences in doing so. Only one presentation was given on e-learning, perhaps surprisingly so as online learning is topical worldwide.

- Sepideh Stewart: Student Reactions to an Approach to Linear Algebra Emphasising Embodiment and Language

- Ann O'Shea, Sinead Breen, Kirsten Pfeiffer: An Evaluation of the Impact of Non-Standard Tasks on Undergraduate Learning

- Jeremy Zelkowski: Student Accountability \& Instructor Variability: A research study in a terminal, required, applications focused calculus course.

- James Musyoka, Joyce Otieno, David Stern: Using e-learning to engage Mathematics and Statistics Students in a Kenyan University

- Ciriaco Ragual \& Ester Ogena: Difficulties and Coping Mechanisms in Solving Mathematics Problems

- Diez-Palomar Javier: Family math education: New trends and possibilities for in the realm of mathematics at tertiary level (Poster) 
- Haitham Solh: Strategies for Effective Teaching and Learning in Collegiate Mathematics Service Courses for Diverse Students (Poster)

- Ildar Safuanov: Design of a system of teaching elements of group theory (poster)

\section{Session 4: Transition from School to University}

Transition from school to university is a general problem as became apparent during this session. Ansie Harding gave the first presentation describing the problem faced in South Africa in this regard. Other presentations described transition problems experienced elsewhere in the world.

- Ansie Harding: On the horns of a dilemma: The transition from school to university in South African

- Randall Pyke: Initiatives at Simon Fraser University in First Year Mathematics and in the Transition from High School to University

- Lee Ji hyun: The Secondary-Tertiary Transition of the Axiomatic Method

- Hoda Ashjari: Recognising Texts in Undergraduate Mathematics Education

\section{Conclusion}

The four sessions were well-attended and enjoyed by all those who attended. New ties were established and collaboration possibilities were communicated.

Open Access This chapter is distributed under the terms of the Creative Commons Attribution Noncommercial License, which permits any noncommercial use, distribution, and reproduction in any medium, provided the original author(s) and source are credited. 